\title{
Influence of Food Supplements on Testing for HIV and Aids and Adhering to Treatment in a Resource Poor Rural Setting: A Case of Chivuna, Southern Zambia
}

\author{
Harriet Ntalasha ${ }^{1}$, Jacob R. S. Malungo ${ }^{1}$, Sonja Merten $^{2}$, Simona J. Simona ${ }^{1}$ \\ ${ }^{1}$ The University of Zambia, School of Humanities and Social Sciences, Lusaka, Zambia \\ ${ }^{2}$ Swiss Tropical and Public Health Institute, Department of Epidemiology \& Public Health, Socinstrasse 57, Basel CH-4002, Switzerland
}

Email address:

harriet.ntalasha@unza.zm (H. Ntalasha), shyakumenzya@hotmail.com (J. R. S. Malungo), Sonja.merten@unibas.ch (S. Merten), simona.simona@unza.zm (S. J. Simona)

\section{To cite this article:}

Harriet Ntalasha, Jacob R. S. Malungo, Sonja Merten, Simona J. Simona. Influence of Food Supplements on Testing for HIV and Aids and Adhering to Treatment in a Resource Poor Rural Setting: A Case of Chivuna, Southern Zambia. Science Journal of Public Health.

Vol. 3, No. 3, 2015, pp. 314-320. doi: 10.11648/j.sjph.20150303.13

\begin{abstract}
Background: There is a serious dearth of literature, particularly on Zambia, on the influential role of food supplements on people's decision to take up an HIV test, start and adhere to AIDS treatment. Methods: Using data from a large ethnographic qualitative study in a resource poor rural setting in Zambia, this paper examines and documents the critical role of food supplements in influencing people to go for HIV testing, initiate treatment and stick to it. Results: Findings show that people who felt food insecure were reluctant to go for a test, thereby not accessing treatment and care services. The narratives revealed numerous aspects of food supplements, HIV testing, ART uptake and adherence, including desire to have access to food due to food insecurity, hoping and wishing to be found positive to access food, envying the HIV positive accessing food, desiring to have physical transformation and healthy-looking bodies enabled by increased access to food, reluctance and avoidance of taking the drugs without food, and worries about food once on medication. Conclusion: The study has shown a close link between food supplements, willingness to test, start taking medication and adherence. Therefore, food supplements should be made an integral part of HIV and AIDS related services in resource poor settings. This means devising more sustainable cross-sectional approaches to foster food security and general livelihoods, such as initiation of income generating activities among vulnerable rural poor, particularly those living with HIV and AIDS.
\end{abstract}

Keywords: Zambia, HIV and AIDS, Food Supplements, HIV Testing, Adherence, ART

\section{Introduction}

Access to Voluntary Counseling and Testing (VCT) is critical in HIV hyper endemic areas and also important from two perspectives, namely, public health and human rights. In the context of public health, VCT averts further spread of the disease in the wider community while human rights component demands that individuals should be provided with health care when in need. Also, VCT is increasingly being recognized as an important entry point to the prevention and care services [1]. By promoting VCT services HIV prevention will be fostered, help prevention of mother-tochild transmission and help increase the use of appropriate health services for treatment of opportunistic diseases associated with AIDS [2]. From the human right perspective, people have the right to know their sero-status and depriving them the access means depriving them of this important information [3-4].

In the same vein, adherence to treatment is very important because available evidence shows that non-adherence, even as little as 1 week, may result in rapid progression to AIDS leading to treatment- failure or drug resistance and death [56]. Adherence on the other hand has led to declining morbidity and mortality among patients with advanced HIV [7].

For the above reasons, therefore, having access to VCT services and ensuring that people stick to medication once they start is very important. Hence the need to investigate, understand and harness all the factors that can encourage people take up early diagnosis in order for those eligible for ART to access appropriate HIV and AIDS-related treatment early enough. Many studies have been carried out in Sub- 
Saharan Africa [8-10] and elsewhere [11] in Haiti to investigate how such factors like distance to VCT/A RT centers and related transport cost, confidentiality of staff, availability of free ARVs, side effects, inadequate staffing and waiting times, lack of infrastructure, cultural milieu, local illness ideologies and testing equipment can influence access to testing and adherence. Such studies, however, have not provided documentation on the influence of food supplements on HIV testing, let alone adhering to treatment.

To our knowledge, very few studies have been carried out so far to specifically examine the association between people's willingness to take up HIV testing and availability of food supplements. One such study, which, though not really focusing on this association but at least made an effort in part to investigate it, is the Zimbabwean study [12]. In this study, the authors made a strong contention that there was a relationship between availability of food supplements and testing. Similarly, [13] in their Zambian study in an urban setting ,also did mention of the link between nutritional support and adherence.

Despite such efforts and contentions, we feel there is still a serious dearth of literature in this area particularly for Zambia. So far there has been very little examination if any, of the extent to which provision of food supplements can act as a factor influencing for HIV testing. This is despite the fact that the Zambian Government, in collaboration with other partners, including World Food Programme (WFP) and community- and religious-based organizations, have been for at least two decades now providing such supplements to chronically ill patients, especially those suffering from tuberculosis and AIDS. The policy guidelines in the aspect have mainly been based on humanitarian considerations for the poor. This paper is therefore, an attempt to provide an understanding of why and how availability of food supplements can actually encourage particularly vulnerable people to take up testing and also to continue taking the life prolonging antiretroviral (ART) drugs in a resource poor setting.

\section{Methods}

\subsection{Study Area and Population}

The study was carried out in Chivuna, a rural community located approximately $60 \mathrm{~km}$ South-East of Mazabuka town, $35 \mathrm{Km}$ from the Great North Road and about $70 \mathrm{~km}$ South of Lusaka, the capital city of Zambia. The main ethnic group is the Tonga speaking (or $B a$-Tonga in plural), a matrilineal and patrilocal group of people. Chivuna has a population of approximately 19000 scattered in an area covering about 34 square kilometers. The main source of livelihood is subsistence farming, which is seasonal and depended on the rainfall pattern. Like most rural areas in Zambia, poverty levels are quite high, averaging more than seven people in ten being poor and having limited access to basic necessities, including food and health. While nearly all the health facilities in the area offer VCT, ART services only exist at
Chivuna and Mbayamusuma health facilities, the two facilities with a distance of more than $40 \mathrm{~km}$ apart. While provision of ART has been there at the latter health facility for more than five years, it was only introduced in 2009 and the only CD4 count machine that had been provided by an NGO was by study time relocated to a bigger health facility, Chikankata Mission Hospital, located about $50 \mathrm{~km}$ away

\subsection{Data Collection and Analysis}

The data presented here was part of a bigger qualitative, ethnographic study conducted over a period of one and half years on people's experiences and views related to testing, ART uptake and adherence. The study used a descriptive and exploratory design including qualitative approaches such as participant observation, key informant interviews (KIIs) (8), focus group discussions (FGDs) (15), and in-depth interviews (IDI,) (30). Both the tested and not tested persons were included. The objective was to collect not only people's perceptions but also, and importantly, their lived experiences. All interviews except for Key informants were conducted in Chitonga (the local language of the area). To recruit study participants, purposive sampling was used by use of snowball technique (through contact persons within community, ART program, the church and traditional healers and herbalists). All the PLWIV identified through this method were first contacted and asked if they could agree to participate in the study. For health facility based interviews, exist interviews were used to identify potential participants.

For the purpose of quality control, all focus group discussions were moderated by the principal investigator who is fluent in the local language. With permission from the study participants, interviews were also tape recorded and transcriptions done as soon as possible to avoid any loss of data. Repeated observations were conducted at the health facility and some of the areas of focus were the heath care provider - client interaction, availability of equipment and drug supplies, physical space, provider-patient relationships, staffing, time of reporting and counseling sessions. All interviews conducted in the local language were transcribed and interpreted into English after which all data were put into a word processing application version and analyzed using ATLAS-TI version 6 using grounded thematic coding, starting with open coding after which all the codes were grouped into similar categories. From these categories, themes were generated. Ethical approval for the study was obtained from the Research Ethics Committee at the University of Zambia and also cleared by the Ministry of Health. For all the individuals that took part in the study, informed consent was sought and all the identities were anonymous.

\section{Results}

\subsection{The Status of Nutritional Food Supplements in the Study Area}

The government of the Republic of Zambia (GRZ) and its 
collaborating partners has agreed on a national nutritional support package to give eligible individuals per month, a High Energy and Protein Supplement (HEPS). HEPS comprises 2.5 liters of cooking oil, $25 \mathrm{~kg}$ mealie meal, $10 \mathrm{~kg}$ beans, $5 \mathrm{~kg}$ groundnuts and $5 \mathrm{~kg}$ Kapenta (small fish). For Chivuna, this pack was provided by a community and religious-based non-governmental (NGO), Churches Health Association of Zambia (CHAZ). At the beginning of the study in 2009, WFP also did provide food supplements but the support had since stopped. . Others also mentioned that the supplies had just run out of the supplements. For Mbayamusuma, a community-based non-governmental organization, Peri-urban Support Programme (PUSH) provided the food supplements in 2008 but had since suspended the provision also. In the whole locality the governmental per se was not mentioned to be involved in the provision of the supplements. At the time of the study, there were 145 beneficiaries of the nutritional support at Chivuna ART center. The eligibility criterion used was vulnerability, that is, the very old, very sick, very poor, not improving on CD4 count in three months and orphans in the age range of 0 14 years old. However, there were reports of delays in distribution and the supply not consistent. It was also reported that at times, the food package was not provided in full.

When the principal investigator visited the food storage facility, inadequacies and insufficiencies were observed. Additionally, at the times of giving out the food supplements, many eligible people were found lining up and struggling to get at least some portion of the supplements. Some community members also accused some health care providers and ART supporters of benefiting more from the supplements than the clients themselves. Such accusations, were however, refuted. Rather the authorities pointed to the inconsistent and inadequate supplies as the main drawbacks. It was also said that instead of only the eligible persons using such food stuff in the households, all the members, regardless of the number and health status started depending of this pack.

The informants mentioned the dire need of the food because the rainfall in the region had for years been aversive and the animals killed by the prolonged disease burdens. Some who had had some support from extended family members were also experiencing shortfalls and inconsistencies due to similar pressure on those providing the support and also due to waning extended family ties in an urbanizing and modernizing country. In other words, the demand for basic necessities per households in Zambia has increased since the national economy was liberalized from the mid-1990s. That is, till now, all the individuals, except for health services for the under-five and those aged beyond 60 years and limited educational bursaries, have to pay for all the basic needs, especially health, education, shelter and food. The national social welfare system for the vulnerable people is riddled with structural and administrative rigidities and serious inadequate resources.

\subsection{Influence of Food Supplements on HIV-Testing}

Nearly all respondents, including health care providers, ART clients and community members strongly felt that availability of food supplements was a potent motivator not only for testing, but for ART up take and adherence. Many attributed this to the poverty levels in the area which generally affected the food security for many households. It was reported that at times, the situation was so desperate that a positive HIV test result was preferred as it was viewed as a gate way to accessing some food. The pressure in the rural setting was more rife as the residents were not salaried monthly. Rather, the subsistence farming system was insufficient to deal with the prevailing hunger situation in the area. Instead of getting labour supplements from their children, these had moved away in search of more amicable urban or other agrarian areas. Even in their places of destination, the children had also been hampered from supporting people at their places of origin due to similar national economic hardships. The limited opportunity to access food, albeit through supplements from HIV-testing was seriously considered by the respondents. The statements below illustrate the perceived role of food supplements on testing:

But madam, (referring to the researcher), the food issue has very important role to play in motivating people to go for VCT and adherence to medicines. Sometimes people even prefer to be found positive so that they can have access to food and become very annoyed when they are found negative. You hear them saying 'Tiimwapima kabotu bulwazi nkobuli mumubili, (You did not conduct the test properly, I am sure the disease, referring to HIV and AIDS, is there in my body), (ART supporter, Community based KII, 2010).

Asking how one respondent on ART came for testing, she said:

I was encouraged by my children to come for testing and I also wanted to have access to food because I am a poor person (Female ARV user, clinic-based, IDI, 2010).

The views on the need for food were not confined to women. Men especially that they are traditionally expected to provide all the basic needs, are equally concerned about the food:

People take drugs because they went to prolong life so that they can take care of their children or prepare for their families; availability of food also encourages people to continue taking their drugs. If somebody has no food there will be no encouragement to go for VCT or continue with the drugs because of the hunger from ARVs. Most people have also heard about the problems arising from taking these drugs like the same hunger issue I have talked about, so they get demotivated to go for VCT because they will start worrying where they would get food from if found positive, (Community-Based male, IDI, 2010).

Health care providers were also cognizant of the role food supplements played in HIV-testing. They therefore, lamented that such packages were no longer provided for their clients: 
When we were still getting nutritional support from CIRDZ, adherence was not a problem and that time I also saw a lot of people coming for testing (Health care provider, KII, 2010).

It was reported that the food situation usually became desperate particularly in the months of December and January because this was the time that most households ran out of food and the crops for that particular season had not yet ripened. Many ART clients narrated how some community members teased them and called them all sorts of names each time they saw them carrying food from the clinic but at the same time envied them and came to beg from them, with some of them going for testing.

Even after testing for HIV, the issue of food insecurity haunts the poor people. This of course affects levels of adherence during treatment. This means that nutritional support does not only influence people's willingness to test for HIV but also their decision to start taking the life prolonging medicines. To a great extent, this fear was due to what they had heard about the drugs from those who were already on the drugs, needing adequate food before and after taking the medication. This is shown in a statement from another male ART user when he stated:

The other problem that troubled me was lack of food because at the time that I was tested, we were told there was no food at the clinic. So I started thinking to myself, if I start taking the ARVs how will I manage without food because I used to hear from those who were taking them complain about too much appetite and hunger as a result of the medicines. So I was worried.

It should also be stated here that while some people had first-hand information about the side effects of the medicines arising from lack of food, for others it was as a result of rumors and community talk circulating within the community. To some extent, the rumors were not only about the side effect of taking drugs without food but led to the belief that the diet to be taken by somebody on HIV and AIDS medication consisted of expensive foods such as meat, chicken, milk and eggs. Such rumors and beliefs militated against some people's willingness to take up testing and to commerce medication once found positive and eligible for medications.

\subsection{Influence of Food Supplements on Adherence}

The research team wanted also to discover whether food supplement had any specific bearing on adherence. The discussions that ensured revealed that provision of food nutrients was as associated with adherence as was the case with HIV-testing. Therefore, when those on medication were asked the question, "What encourages you to take your medicines as prescribed to you by your health care provider?" a number of them identified availability of food provided by the health facility as one of the factors that helped them to do so. In fact when compared with testing and ART up take, the need for food was even more in adherence because it was no longer an imaginary one but a reality. Therefore, though they were able to identify several other factors such as desire to live and look after one's children, having reminders, some of the participants even identified availability of food as being number one driver for drug compliance.

For instance, during one of the in-depth individual interviews, a female ART user noted:

Number one is the food that I get from the clinic. I am a poor person, without this food I do not know how I could have managed because those drugs cause a lot of appetite and if you do not have food, you can cause other problems in your body. Then secondly, I really need life, I want to prolong my life so that I can work for myself as I used to before and see my child grow before I die.

These views were reiterated by several other community members and health care providers working in the area. Some of the health care providers had worked in the area for a long period of time and were therefore able to attest to increasing poverty levels in the area over a period of time. One of the factors mentioned for this scenario was persistent cattle disease which had led to decimation of most of the animal which were used for draught power. As a result many have resorted to hoe cultivation, a very limiting agrarian farming system. Use of hoes was a very common but severe challenge among most community members and worse among those who were sickly or just recovering from some illness.

The other factor mentioned contributing to the rising poverty in the area was the lack of access to the market. This was as a result of the liberalized market economy which has exposed many small scale farmers to unscrupulous businessmen. This scenario has been worsened by the poor road network in the area. The connect of these rural economic hardships to food supplements is that such unprecedented collapses in both crop and animal agricultural systems have stressed the rural villagers to a level of envying food provided at the AIDS-related programmes.

Additionally, many ART clients mentioned that they had become poorer after being bedridden for some time. Some of them reported that while they were not able to engage in meaningful agricultural production for the time they were sick and they used up whatever small savings for consumption had accumulated. This was clear from quotes from a focus group discussion with female community members, when they stated:

Bucheteingabulaindilila (poverty becomes worse) because what happens is that when one has AIDS they like kulyabwino (eating well) so they would start spending their savings on those nice food stuffs. Also sometimes when going to the clinic especially for those who still cover long distances to reach an ART centre, you may need to have transport money. So you find yourself selling a goat or chicken either for transport money or to buy some nice food stuffs or you need to go to a witchdoctor who demands for some payment. Even eating chickens or goats because AIDS-patients like to eat blood foods (flesh) a lot (Elderly woman).

Some community member inferred that food supplements were needed among the households with some sick people 
because family labor was affected, meaning less production.

It was also revealed from different sources that although free ARVs were available, a number of people still delay to test due to the various barriers that they were faced with. This meant that they only accessed ART when they had already become too sick and are therefore off production for some time and hence the need for food supplements when they start taking the treatment.

Viewed within the context of poverty therefore, most respondents strongly felt that provision of food supplements was critical to facilitate adherence. However, many respondents were quick to mention the challenge involved in providing food supplements amid an increasing number of ART clients in need of the same. They were therefore, emphatic on the need to give the clients who recover some sustainable source of livelihood so as to reduce dependence on food supplements from the health facility. This was elucidated by one of the male health care providers when he narrated:

Provision of food supplements is very important for people taking medicines, it encourages them to take their medicines consistently otherwise they may stop because of side effects. Many of them have experienced increase of appetite especially when one starts feeling better. You see one of the biggest challenges we have in this area is poverty and when we talk about poverty we mean that most of the people in this area are very poor here. This means that nearly all of them need food supplements and we are not managing. The situation for us has even been worsened by the withdraw of WFP and so we have just remained with the food from $\mathrm{CHAZ}$ which is not enough. This is why for me I feel that giving these people handouts is not really helping the situation, I think as those who recover and graduate, they should be supported in some kind of income generating activities.

Study participants on ART equally shared the view about sustainable assistance. This was for a number of reasons. Firstly, many of them were aware that they were not the only ones in need of food nutrients. Secondly, they also appreciated the difficulty faced by the facility to provide food for an increasing number of ART clients. Lastly, they wanted to get out of the shame and embarrassment that came with free food, which made many of them have some feelings of change in their social status from that of self-reliance to that of being "beggars". They stated that that they longed to be able to take charge of their lives and be able to fend for their families again. While being supported by all the group members, a 61-year old male support group member, who was also the chairperson, expounded his views:

We appreciate the food the government is giving us, but at times it is very embarrassing and dehumanizing for big people like us to be lining up for food, we have become beggars or like small children who are unable to look after themselves. We need fertilizer and seed so that those of us who have become stronger can be able to grow food for ourselves instead of the government to continue giving us food, you can imagine carrying these (pointing at a 2.5 litres container) for cooking oil each time we come here, if we grow enough food for ourselves we can be able to sell part of it, buy ourselves cooking oil and all the nutritious food we need. Only those lazy people would want to continue getting free food even after they have recovered. We formed a support group but we do not have enough capital to start a meaningful income generating activity.

Inconsistencies and inadequacies were also reported in the supply of this most required commodity. For instance, it was reported that sometimes the nutritional support did not come on time while at times it was not enough to cater for everyone who was eligible. This made it difficult at times for the health care providers to register new people into the program even when they desperately needed the food. At one of the health facilities, the nutritional support was at the time of the study no longer available. Yet many study participants on ART lamentably explained how difficult it was to take the medicines without food. A widow in her late sixties who was on ART and not a beneficiary of food supplements remarked:

As I said in ART uptake, lack of food has been the major barrier. You know these medicines are very strong so you take them without food in the body you feel like you are running mad. Some of our friends are lucky because they have continued getting food from the clinic, some of us have nothing, at least they do not have to worry about food to go with their medicines.

Inadequate supply of food supplement support was identified as a big challenge because according to most study participants, nearly all the people on ART needed nutritional support due to high poverty levels in the area .Additionally, it was reported that community support for the sick was no longer there because of the of dying spirit of giving among community members. Accordingly, the support spirit had been eroded away by high poverty levels affecting the area. This meant that in the event that one was too sick to provide for oneself, there was no guarantee of getting any assistance from other community members and hence the much reliance on the food from the health facility.

According to some study participants, particularly ART clients and others from the community, however, the inadequate supply of food nutrients was at times artificially created. They stated that the food received was enough to go round for most of the clients in need had it not been for what they referred to as some "greedy health care providers." It was reported that some of these greedy health staff were fond of getting food meant for ART clients for their families while others were reported to be selling.

Reiterating similar sentiments, another discussant retorted:

Yes we see some of them sell items like cooking oil and sugar. You hear some of them saying utakavuvibiliaano a mission takakavubikabili. (who ever won't get rich while here at the Mission health facility will never be rich in their lives).

Other concerns raised as regards the food nutrients were the long distances clients were required to cover in order to access the food and carry it home on their heads. Observations showed that some of these clients came from 
communities located over $50 \mathrm{~km}$ away from the food storage facilities and were either too sick or too old to carry the food on their heads. For instance on one of the ART days the research team observed a sickly looking 80 year old woman who after getting the food remained at the facility for hours. The research team had no option but to drive her to her home village located more than $20 \mathrm{~km}$ away. The old woman narrated that in most cases she spent a night at the facility if there was no "Good Samaritan" going her direction while at times she had to depend the Parish priest to go her direction.

\section{Discussion}

Data from this study have shown that provision of food supplements facilitates and did swing the balance in favor of uptake of HIV-testing and drug compliance. This was mainly because, with the guarantee of food supplements from the health facility, peoples' worries about finding food and the risk of taking medicines without food once found positive were reduced. The findings also imply that without food supplements, some people may not utilize the VCT services even when they may be located nearby. It is also clear from the findings that the situation in the study area was worsened by chronic high poverty levels. Additionally, the culture of giving others by community members has been eroded by the rising poverty levels. This means that unlike in the past when those in need of support, such as the terminally ill, would fall on the other community members for support, this was slowly dying out. This finding is in line with that of [14] in the same area. Additionally, the findings show that those who recover after a long illness often found themselves in a worse off situation than before they became sick.

Viewed within the context of poverty, therefore, dealing with factors like reducing distance to VCT/ART center and provision of free HIV and AIDS-related services should be accompanied with the provision of food supplements. This is critical if people are to be encouraged to access and effectively utilize the available services. Even the shame associated with begging when receiving the food is overshadowed by the dire need for the food, to test and also to continue taking the medication. The findings from this study mirror those of other researchers from other countries within the sub-region such as the Zimbabwean study [12]. Commenting on the role of food in encouraging VCT, these authors state that anticipation of food aid benefits resulted in some people accessing VCT in the hope of qualifying for food aid and also with some clients apparently feeling disappointed when they test negative for HIV. The authors however, note further that in countries where poverty and hunger were pervasive, individuals may focus on the short term benefits of qualifying for food aid over the long term ramifications of being HIV positive. They conclude therefore that when offering food relief, there was need to be aware of this potential connection between poverty alleviation and HIV testing. Studies from other parts of the world such as Haiti [15] also report that the provision of food aid can mobilize people to go for HIV testing.
The findings also should underpin the need to mount more economic support programmes among the rural poor. This may take the form of providing soft loans for the vulnerable households or/and initiating sustainable income generating ventures. In addition, such activities, in the context of HIV and AIDS, should be accompanied by various therapeutic measures, to not only point the persons involved to the longterm aspirations of eradication poverty, but equally important HIV and AIDS.

The data from this study have also shown a close association between availability of food supplements and drug compliance. This association has been identified before in earlier studies carried out in Sub-Saharan as a factor leading to compliance while lack of it leads to treatment interruption: Botswana [9, 13 and 16].These studies report that because of the side effects arising from the use of ARVs, some ART clients found it difficult to continue taking the medicines without interruptions. To encourage drug compliance and avoid some of the problems related to nonadherence, therefore, supplying of food supplements, particularly for resource poor setting like the study area would be a very important factor to be considered.

What the study is suggesting that there should be expansion of programmes involved in provision of food to the needy in terms of mobilizing more providers and also having consistent and adequate supplies. This need may be costly in the recruiting and training of the needed human resources but will have desired dividends in the long run. This is especially if the programmes take more holistic approaches to provision of more sources of livelihood. All the gate keepers, notably the traditional, religious, civil and community leaders should galvanize all their efforts to not only prevent the spread of HIV and AIDS by encouraging testing but also avert more deaths through the provision of the diverse social and economic incentives and services to the most vulnerable rural poor.

\section{Conclusion}

The findings from this study have shown that a very close link exists between availability of food supplements and people's willingness to test for HIV, and also continue taking the ART drugs without interruptions. Any factor that facilitates early testing is important as this can facilitate people's early access to appropriate HIV and AIDS treatment and care. Similarly, investigation of factors that encourage people to comply with medication is important as this would help reduce treatment interruptions. This would subsequently contribute to a reduction in deaths among ART users because lack of adherence does not only lead to possible ineffectiveness of treatment but increases risk of resistance to medication [6, 17]. Additionally, every time one becomes resistant to a drug, options for treatment are reduced. Having revealed a close relationship between food supplements, testing and adherence, therefore, food supplements should be made an integral part of HIV and AIDS related services. However, to avoid perpetual dependency, perhaps this should 
be made in a more sustainable manner. This means devising more sustainable cross-sectional approaches to foster food security and general livelihoods, such as initiation of income generating activities among vulnerable rural poor, particularly those living with HIV and AIDS. As a strategy for further alleviation of poverty in the area, there would be need to improve the road network so as to improve access to markets. Other issues worth mentioning include the need to increase staffing at the health institutions and more HIV and AIDS-related services would need to be up scaled.

\section{Acknowledgements}

This study was part of the ART access project and it was by funded by The Swiss National Science Foundation (SNF) through the Swiss Tropical and Public Health Institute. We acknowledge this funding. We also acknowledge the support from our host institution, the University of Zambia for the space and time to work on this paper. The views expressed in this paper are entirely those of the authors.

\section{References}

[1] Grant, E., D. Logre, D. Gorman, S.A. Murray (2008). Factors facilitating and challenging access and adherence to antiretroviral therapy in a township in the Zambian Copperbelt province, A qualitative study. AIDS Care, 20(10), 1155-1159.

[2] Babalola, S. (2007). Readiness for HIV Testing among Young People in Northern Nigeria: The Roles of Social Norm and Perceived Stigma. AIDS Behav (11) 759-769.

[3] Fylkenes, and Siziya, S. (2004). A randomised trial on acceptability of voluntary HIV counseling and testing. Tropical Medicine and International Health (9):566-572.

[4] Jackson, H. (2002). AIDS Africa, Continent in crisis, SAFAIDS, SIDA, UNFPA, Avondale Harare, Zimbabwe.

[5] Weiser, S., Wolfe, W., Bangsberge, D., Thior, I., Gilbert, P., Makhena, J., Max, E., and Marlink, R. J. (2003). Barriers to antiviral adherence for patients living with HIV infection in Botswana. Journal of Acquired Immune Deficiency Syndrome 34:281-280.

[6] Bangsberge D R, Perry S and Charlebois E, D. (2001). Nonadherence to highly active antiretroviral therapy predicts progression to AIDS and death. AIDS (15) pp. 1181-1183.
[7] Hogg, R. S, Heath K and Bangsberge, D. R. (2002). Intermittent use triple-combination therapy is predictive of mortality at baseline and after 1 year of follow-up. AIDS 16, pp. 1051-1058.

[8] Murray, L.K., Semrau, E., McCurley, D. M., Thea, N. Scott \& P. Bolton (2009). Barriers to acceptance and adherence of antiretroviral therapy in urban Zambian women, a qualitative study. AIDS Care, 21(1), pp78-86.

[9] Hardon, A.P. Akurut D., Commoro C., Irude H. F., Gerrits T., et al (2007), Hunger, Waiting Time and Transport costs: Time to Confront challenges to ART adherence in Africa, AIDS Care 19(5), 658-665

[10] Malungo, J. R. S. (2001). Sexual cleansing (Kusalazya) and levirate marriage (kunjililamunganda) in the era of AIDS, challenges in perception and practices in Zambia. Social Science and medicine 53(3), 371-382.

[11] Farmer P, Leander F, Mukherjee J S, Sidonise M, Nevil P, Smith- Fanzi M C, Koenig S, Castro A, Becerra M C, Sachs J, Attaran A, Yong Kim J (2001) Community-based approaches to HIV treatment in resource poor settings. The Lancet, 358, pp. 404-409.

[12] Chirawu P., Langhaug, L., Mavhu W., Pascoe S., Dirawo J., Cowan F. (2009). Acceptability and Challenges of implementing voluntary counseling in rural Zimbabwe, evidence from the Regaidzive Shiri Project. Rutledge, 37-41, Mortimer street, London, WIT 3JH, UK.

[13] Sanjobo, N., Frich Jan C. and Fretheim , A. ,(2008), Barriers and Facilitors to patient adherence to antiretroviral treatment in Zambia ,a qualitative study. Journal of Social aspects of HIV/AIDS, Volume 5 (3); pp 136-142

[14] Ntalasha, H. (2000) Savings among the rural poor, a case of Chivuna Southern province, FAO, Lusaka, Zambia

[15] Mukherjee, J.S., L. Ivers, F. Leandre, P. Farmer \& H. Behforous (2006). Lippincott Williams and Wilkins, Acquired Immune deficiency Syndrome, 43, Supplementary 1,. 3123 3126 .

[16] Mshana Gerry H., Wamoyi, J., Busza J., Zaba, B., Changlucha, J., Phil M., Kaluvya, S., and Urassa, M., (2006). Barriers to accessing anti-retroviral therapy in Kisesa, Tanzania: A qualitative study of Eearly Rural Referrals to the National Programme. AIDS Patient Care and STDs. 20 (9) 649-655.

[17] Oyugi, J. H, Byakika-Tusiime, J., Ragland, K., Laeyendecker, O., Mugerwa, R. , Kityo, C., (2007) Treatment Interruptions predict resistance in HIV positive individuals purchasing fixed dose combination antiretroviral therapy in Kampala Uganda, AIDS. 21:965-971. 